\title{
Effect of repetitive episodes of exercise induced myocardial ischaemia on left ventricular function in patients with chronic stable angina: evidence for cumulative stunning or ischaemic preconditioning?
}

\author{
C A Rinaldi, N D Masani, A Z Linka, R J Hall
}

\begin{abstract}
Background-Myocardial stunning is known to occur following a single episode of effort angina in patients with coronary artery disease. The effect on left ventricular (LV) function of repeated episodes of ischaemia is unknown.

Objectives-To investigate the effects of repeated episodes of exercise induced ischaemia on $L V$ function in patients with chronic stable angina.

Methods-Patients with significant coronary artery disease and normal $\mathrm{LV}$ function underwent two episodes of symptom limited treadmill exercise separated by three different time intervals: either $\mathbf{3 0}$ minutes (group $A, \mathbf{n}=14$ ); 60 minutes (group B, $n=14$ ); or 240 minutes (group $C, n=14$ ). Quantitative stress echocardiography was performed at repeated intervals between the two exercises and for $\mathbf{2 4 0}$ minutes following the second test.
\end{abstract}

Results-For all groups there was no difference between the degree of ischaemia judged by maximal ST depression during the two tests. All episodes of exercise induced ischaemia produced prolonged abnormalities of $\mathbf{L V}$ systolic and diastolic function despite rapid normalisation of haemodynamic and ECG changes. In group A (30 minutes) these abnormalities were less pronounced after the second test than after the first, while in group $B$ (60 minutes) they were more severe and long lasting. In group C (240 minutes) the two tests produced similar abnormalities of $L V$ function.

Conclusions-Prolonged abnormalities of LV function occurred following exercise induced ischaemia with a time course consistent with myocardial stunning. The severity and degree of $\mathrm{LV}$ dysfunction caused by a further episode of ischaemia appear to be dependent on the time interval between ischaemic episodes.

(Heart 1999;81:404-411)

Keywords: ventricular function; exercise; stress echocardiography

Myocardial stunning is the myocardial dysfunction that persists following ischaemia in the absence of necrosis, despite the restoration of blood flow. ${ }^{1}$ Exercise induced stunning has been shown to occur in patients with coronary artery disease following a single episode of effort angina. ${ }^{2}$ The effects of repeated episodes of exercise induced ischaemia on myocardial function in humans are unclear. In chronically instrumented dogs, repeated episodes of exercise induced ischaemia result in cumulative and prolonged abnormalities of contractile function caused by repetitive myocardial stunning. ${ }^{3}$ It has been suggested that the pathophysiology of chronic left ventricular (LV) dysfunction in patients with coronary artery disease may involve this phenomenon of repetitive myocardial stunning. ${ }^{4}$

The present study was designed to investigate whether repeated episodes of ischaemia would produce repeated episodes of myocardial stunning, and what effect this would have on LV function. We set out to determine whether repetitive ischaemia would produce cumulative stunning, or whether this might be attenuated by ischaemic preconditioning. ${ }^{5}$ To do this we examined the effects of two episodes of exercise induced ischaemia at three different time intervals in patients with chronic stable angina.

\section{Methods}

The study protocol was approved by the University of Wales local research and ethics committee and all patients gave full written informed consent.

\section{PATIENTS}

We studied three groups (A, B, and C) each comprising 14 men with angiographically proven coronary artery disease, chronic stable angina, and normal resting $\mathrm{LV}$ function assessed by angiography and confirmed on echocardiography. Patient demographics are shown in table 1.

All subjects underwent diagnostic coronary angiography (demonstrating $>70 \%$ diameter stenosis in at least one major epicardial coronary artery) before and within three months of the study. This was part of their routine clinical management. Patients with a history of myocardial infarction or unstable angina within the past year were excluded, as were those with uncontrolled hypertension and those in whom it was not possible to obtain echocardiograms of sufficient quality for quantitative analysis (at least $75 \%$ of the endocardial border to be 
Table 1 Patient demographics

\begin{tabular}{llll}
\hline & $\begin{array}{l}\text { Group } A(30 \\
\text { mins) }(n=14)\end{array}$ & $\begin{array}{l}\text { Group B (60 } \\
\text { mins) }(n=14)\end{array}$ & $\begin{array}{l}\text { Group C (240 } \\
\text { mins) }(n=14)\end{array}$ \\
\hline Age (years) & $57.5(8.5)$ & $62(5.1)$ & $54.1(5.7)$ \\
Single vessel disease & $2(14 \%)$ & $1(7 \%)$ & $3(21 \%)$ \\
Two vessel disease & $1(7 \%)$ & $1(7 \%)$ & $2(14 \%)$ \\
Triple vessel disease & $11(79 \%)$ & $12(86 \%)$ & $9(65 \%)$ \\
Mean vessel disease & 2.64 & 2.8 & 2.3 \\
Previous myocardial infarction & $2(14 \%)$ & $3(21 \%)$ & $3(21 \%)$ \\
Resting heart rate (beats/min) & $66(11)$ & $70(13)$ & $72(12)$ \\
Systolic blood pressure (mm Hg) & $145(17)$ & $144(14)$ & $147(16)$ \\
Resting EF (\%) & $61(7)$ & $58(8)$ & $62(6)$ \\
Resting IRP (ms) & $87.4(10.8)$ & $98.1(14.8)$ & $80.7(21.7)$ \\
Nitrate & $9(64 \%)$ & $10(71 \%)$ & $8(57 \%)$ \\
Calcium antagonist & $4(29 \%)$ & $6(43 \%)$ & $4(29 \%)$ \\
$\beta$ Blocker & $14(100 \%)$ & $14(100 \%)$ & $14(100 \%)$ \\
& & &
\end{tabular}

Data presented are mean (SD) or number (\%) of patients.

$\star$ Patients with previous inferior wall myocardial infarction only were included.

$\mathrm{EF}$, ejection fraction; IRP, isovolumic relaxation period.

visualised). Several patients with previous myocardial infarction confined to the inferior wall but good overall contractile function were studied.

STUDY PROTOCOL

Each subject performed two symptom limited treadmill exercise tests according to the standard Bruce protocol. Two dimensional echocardiograms were obtained before the first test and at regular intervals between then and for 240 minutes following cessation of the second episode. Pulsed wave Doppler tracings of LV diastolic inflow at the tips of the mitral valve leaflets and a phonocardiogram were recorded simultaneously.

EXERCISE TESTING

$\beta$ Blockade was discontinued for 48 hours before exercise testing (equivalent to five half lives); all other antianginal medications were omitted for the study day. Exercise tests were performed on all occasions using a Marquette treadmill. Patients were advised to avoid all activities known to precipitate their angina for 24 hours before the test and to use prophylactic glyceryl trinitrate if it was possible. Patients who had suffered angina during the four hours before the test were excluded. Three ECG leads (II, V2, and V5) were monitored continuously during the exercise and recovery periods. Blood pressure and 12 lead ECGs were performed every three minutes during exercise and every two minutes in recovery until resolution of ECG changes and a return of heart rate and blood pressure to baseline values. Patients continued exercise until limited by their symptoms. Exercise was also discontinued if any of the following criteria were reached: a drop in systolic blood pressure of $10 \mathrm{~mm} \mathrm{Hg}$, or the occurrence of significant arrhythmias on exercise.

Following the initial exercise test (Ex1) patients performed a repeat exercise test (Ex2) at either 30 minutes (group A), 60 minutes (group B), or 240 minutes (group C) following the end of Ex1. All antianginal medication was restarted four hours after Ex2.

\section{ECHOCARDIOGRAPHY}

After the patient was placed in the left lateral decubitus position, two dimensional echocardiograms were obtained with commercially obtainable equipment (Hewlett-Packard Sonos 1500, Model 77025A; Hewlett Packard Inc, Andover, Massachusetts, USA) using a 2.5 $\mathrm{MHz}$ phased array transducer. All studies were performed by one investigator (CAR). To ensure reproducibility the position of the patient on the couch (degree of backrest angulation and left lateral tilt) was documented at baseline and used for each image acquisition and the position of the transducer on the patient's chest was marked. In order to minimise beat to beat variation all recordings were made in held gentle expiration. Studies were recorded on Super VHS videotape for later offline analysis.

The following observations were made: two dimensional apical two chamber $(\mathrm{AP} 2 \mathrm{CH})$ and apical four chamber (AP4CH); and pulsed wave Doppler tracings of LV diastolic inflow at the tips of the mitral valve leaflets with simultaneous recording of the phonocardiogram (positioned in the second left intercostal space). Images were recorded at rest, immediately following exercise (within five minutes of termination of exercise), and then at 30 minute intervals following Ex1. This was repeated for the second test with images being acquired at 30 minute intervals for 240 minutes following Ex2.

ECHOCARDIOGRAPHIC ANALYSIS

The videotaped images were analysed by two experienced observers (CAR, AZL) using an offline PC based digitising program (Thoraxcenter, Erasmus University, Rotterdam, Netherlands ${ }^{6}$ ). Analysis was performed in a blinded fashion with the observer being blinded to the timing of the study and which group the study came from. Three consecutive beats (excluding extrasystolic beats and postextrasystolic beats) were analysed for each time point in both the $\mathrm{AP} 2 \mathrm{CH}$ and $\mathrm{AP} 4 \mathrm{CH}$ views.

Endocardial contours were traced (excluding papillary muscles) at end diastole timed as the closure of the mitral valve leaflets, and at end systole defined as the point of maximal inward excursion of the endocardial contour. The centreline method was used to assess regional LV function. ${ }^{78}$ The computer superimposes the end diastolic and end systolic endocardial tracings, and calculates a centreline between them. The deviation from the centreline of 100 chords around the LV circumference is calculated, corrected for the end diastolic circumference, and expressed as a percentage shortening fraction (SF). Each apical view of the $\mathrm{LV}$ is divided into six segments and the SF of the chords in each segment is averaged so that a total of 12 values are obtained.

A persistent wall motion abnormality (WMA) was one defined as being present 30 minutes after exercise. In preliminary studies we obtained a $10 \%$ variability in serial measurements of SF in regions that did not develop WMAs; for this study a change in SF from baseline of $>20 \%$ was taken as abnormal - that is, WMA. We calculated SF for all 12 segments (SFmean), for segments with a persistent wall motion abnormality 
Table 2 Exercise data (mean (SD))

\begin{tabular}{|c|c|c|c|c|}
\hline & Exercise 1 & Exercise 2 & $t$ test & Linear regression \\
\hline \multicolumn{5}{|l|}{ Group A (30 mins) } \\
\hline Total exercise time (s) & $388(150)$ & $434(161)$ & $\mathrm{p}<0.001$ & $\mathrm{y}=-0.91 \mathrm{x}-6.2, r=0.95, \mathrm{p}<0.0001$ \\
\hline Time to angina $(\mathrm{s})$ & $252(168)$ & $294(182)$ & $\mathrm{p}<0.05$ & $\mathrm{y}=0.86 \mathrm{x}+3.5, r=0.92, \mathrm{p}<0.0001$ \\
\hline Time to $1 \mathrm{~mm} \mathrm{ST} \mathrm{(s)}$ & $290(167)$ & $360(164)$ & $\mathrm{p}<0.05$ & $\mathrm{y}=0.89 \mathrm{x}-32, r=0.77, \mathrm{p}=0.002$ \\
\hline Maximum ST (mm) & $2(1)$ & $1.9(1.3)$ & NS & $\mathrm{y}=0.71 \mathrm{x}+0.64, r=0.86, \mathrm{p}=0.0001$ \\
\hline Workload (METS) & $7.6(2)$ & $8.6(2)$ & $\mathrm{p}<0.0001$ & $\mathrm{y}=0.89 \mathrm{x}-0.068, r=0.89, \mathrm{p}=0.0001$ \\
\hline Rate-pressure product $(\times 100)$ & $200.6(58.1)$ & $216.4(64.1)$ & $\mathrm{p}<0.05$ & $\mathrm{y}=0.82 \mathrm{x}+235, r=0.82, \mathrm{p}=0.0001$ \\
\hline \multicolumn{5}{|l|}{ Group B (60 mins) } \\
\hline Total exercise time (s) & $342(164)$ & $347(165)$ & NS & $\mathrm{y}=0.89 \mathrm{x}+41.6, r=0.95, \mathrm{p}=0.0001$ \\
\hline Time to angina $(\mathrm{s})$ & $206(110)$ & $224(118)$ & NS & $\mathrm{y}=0.99 \mathrm{x}+19.9, r=0.92, \mathrm{p}=0.0001$ \\
\hline Time to $1 \mathrm{~mm} \mathrm{ST}$ (s) & $222(133)$ & $258(152)$ & NS & $\mathrm{y}=1.1 \mathrm{x}+15.7, r=0.96, \mathrm{p}=0.0001$ \\
\hline Maximum ST $(\mathrm{mm})$ & $2.1(0.9)$ & $1.9(1)$ & NS & $\mathrm{y}=0.86 \mathrm{x}+0.119, r=0.79, \mathrm{p}=0.0007$ \\
\hline Workload (METS) & $6.6(2.9)$ & $6.7(2.6)$ & NS & $\mathrm{y}=0.84 \mathrm{x}+1.1, r=0.96, \mathrm{p}=0.0001$ \\
\hline Rate-pressure product $(\times 100)$ & $217(3.63)$ & $218(5.07)$ & NS & $\mathrm{y}=1.1 \mathrm{x}-2932, r=0.81, \mathrm{p}=0.0004$ \\
\hline \multicolumn{5}{|l|}{ Group C (240 mins) } \\
\hline Total exercise time (s) & $329(144)$ & $332(126)$ & NS & $\mathrm{y}=1.1 \mathrm{x}-38.3, r=0.93, \mathrm{p}=0.0001$ \\
\hline Time to angina $(\mathrm{s})$ & $231(105)$ & $244(148)$ & NS & $\mathrm{y}=1.2 \times 36.5, r=0.85, \mathrm{p}<0.0001$ \\
\hline Time to $1 \mathrm{~mm} \mathrm{ST} \mathrm{(s)}$ & $247(132)$ & $259(95)$ & NS & $\mathrm{y}=1.08 \times 32.3, r=0.78, \mathrm{p}=0.01$ \\
\hline Maximum ST (mm) & $1.8(0.8)$ & $1.43(0.44)$ & NS & $\mathrm{y}=1.05 \mathrm{x}+0.298, r=0.58, \mathrm{p}=\mathrm{NS}$ \\
\hline Workload (METS) & $6.5(2.4)$ & $6.5(2.2)$ & NS & $\mathrm{y}=1.1 \mathrm{x}-0.61, r=0.94, \mathrm{p}=0.0001$ \\
\hline Rate-pressure product $(\times 100)$ & $241(40)$ & $247(58)$ & NS & $\mathrm{y}=0.56 \mathrm{x}-10372, r=0.80, \mathrm{p}=0.003$ \\
\hline
\end{tabular}

METS, metabolic equivalents.

(SFwma), and in normal segments that did not develop wall motion abnormalities following exercise (SFnorm). LV volumes at end diastole and end systole were calculated using the biplane disc method and global ejection fraction $(\mathrm{EF}(\%))$ was derived from these volumes. Analyses of diastolic indices were performed by using a digitising tablet and tracing the Doppler pulsed wave LV diastolic inflow (five consecutive beats for each time point). The isovolumic relaxation period (IRP) was measured as the interval between aortic valve closure as measured from the phonocardiogram and the onset of the $\mathrm{E}$ wave.

\section{STATISTICAL ANALYSIS}

Results are expressed as mean (SD). To detect differences between the two exercise tests a Student's $t$ test was used, and linear regression analysis was performed for comparison of these data. Serial changes in EF, SF, and IRP were analysed using repeated measures analysis of variance (ANOVA) and post hoc testing with Scheffes $\mathrm{f}$ test. For the purpose of this study $\mathrm{p}<0.05$ was considered significant. Statistical analysis was performed on a Power Macintosh
Computer (Apple Computers Inc, Cupertino, California) using Statview $512^{+}$(Abacus Concepts, Berkeley, California).

\section{Results}

There were marked changes in LV function in the results obtained when exercise was repeated at the three different time points, and these changes were very different at each time point.

\section{GROUP A (30 MINUTE GROUP)}

Exercise data

Exercise results are shown in table 2. Both exercise tests were completed by all 14 patients. All patients had positive exercise tests fulfilling the criteria of $1 \mathrm{~mm}$ of exercise induced ST depression and developed typical cardiac pain which limited exertion. Exercise time, time to angina, time to $1 \mathrm{~mm} \mathrm{ST}$ depression, workload, and rate-pressure product, were all significantly improved with Ex2. Maximum ST depression was unchanged.

Table 3 Echocardiographic data (mean (SD))

\begin{tabular}{|c|c|c|c|c|c|c|c|c|}
\hline & \multirow[b]{2}{*}{ Pre-exercise } & \multicolumn{3}{|l|}{ Exercise 1} & \multicolumn{4}{|l|}{ Exercise 2} \\
\hline & & 30 mins post & 60 mins post & 240 mins post & 30 mins post & 60 mins post & 120 mins post & 240 mins post \\
\hline \multicolumn{9}{|c|}{ Group A (30 mins) } \\
\hline SFwma & $3.84(0.56)$ & $2.65(0.69)^{\star \star \star}$ & & & $3.1(0.56)^{\star}$ & $3.33(0.7)$ & $3.5(0.8)$ & $3.8(0.5)$ \\
\hline SFmean & $3.79(0.59)$ & $3.25(0.67)^{\star \star \star}$ & & & $3.58(0.7)$ & $3.7(0.6)$ & $3.7(0.6)$ & $3.8(0.5)$ \\
\hline Sfnorm & $3.7(0.7)$ & $4(0.9)$ & & & $3.8(0.7)$ & $3.8(0.7)$ & $3.9(0.7)$ & $3.9(0.7)$ \\
\hline $\mathrm{EF}$ & $61(6.9)$ & $55(8.9)^{\star \star \star}$ & & & $58.2(8.8)$ & $59(8)$ & $61(7)$ & $62(8)$ \\
\hline IRP & $87.4(10.8)$ & $105.2(10.8)^{\star \star \star}$ & & & $93(10.6)$ & $92(12)$ & $90(10)$ & $87(10)$ \\
\hline \multicolumn{9}{|c|}{ Group B (60 mins) } \\
\hline SFwma & $3.31(0.74)$ & $1.86(0.75)^{\star \star \star}$ & $2.81(0.85)^{\star}$ & & $1.59(0.76)^{\star \star \star}$ & $1.99(0.67)^{\star \star \star}$ & $2.52(0.76)^{\star \star \star}$ & $3.03(0.68)$ \\
\hline SFmean & $3.34(0.5)$ & $2.63(0.59)^{\star \star \star}$ & $3,12(0.64)$ & & $2.4(0.78)^{\star \star \star}$ & $2.5(0.65)^{\star \star \star}$ & $2.9(0.52)^{\star}$ & $3.33(0.46)$ \\
\hline SFnorm & $3.64(0.9)$ & $3.68(0.8)$ & $3.71(0.9)$ & & $3.5(0.9)$ & $3.18(0.8)$ & $3.25(0.6)$ & $3.81(0.6)$ \\
\hline $\mathrm{EF}$ & $57.6(8.1)$ & $48.9(13.2)^{\star \star \star}$ & $53.8(9.9)$ & & $45.7(12.5)^{\star \star \star}$ & $49(10.6)$ & $52.5(9.6)$ & $56.4(8.7)$ \\
\hline IRP & $98.1(14.8)$ & $115.2(15.2)^{\star \star \star}$ & $108(15.3)^{\star \star \star}$ & & $\begin{array}{l}121.9 \\
(11.3)^{\star \star \star}\end{array}$ & $122(12.2)^{\star \star \star}$ & $116.6(15.7)^{\star \star \star}$ & $100.3(15.1)$ \\
\hline \multicolumn{9}{|c|}{ Group C (240 mins) } \\
\hline SFwma & $4.29(1)$ & $2.8(1)^{\star \star \star}$ & $3.99(1)$ & $4.07(0.86)$ & $3(0.9)^{\star \star \star}$ & $2.84(0.82)^{\star \star \star}$ & $3.5(1.1)$ & $4(1.3)$ \\
\hline SFmean & $3.85(0.57)$ & $3.23(0.71)^{\star \star \star}$ & $3.75(0.59)$ & $3.85(0.64)$ & $3.4(0.75)^{\star \star}$ & $3.62(0.77)$ & $3.8(0.8)$ & $3.8(0.8)$ \\
\hline SFnorm & $3.6(0.8)$ & $3.6(0.8)$ & $3.7(0.6)$ & $3.6(0.9)$ & $3.5(0.9)$ & $3.5(0.9)$ & $3.6(0.9)$ & $3.8(0.6)$ \\
\hline $\mathrm{EF}$ & $62(5.7)$ & $54.1(7.5)^{\star \star \star}$ & $60(5)$ & $61(6.2)$ & $56(9.2)^{\star \star \star}$ & $59.9(6.6)$ & $60(7)$ & $61(7)$ \\
\hline IRP & $80.7(21.7)$ & $93.2(16)^{\star}$ & $93.5(19.6)^{\star}$ & $84.1(19.2)$ & $91.5(13)^{\star}$ & $95.7(12.6)^{\star}$ & $92(23)^{\star}$ & $81.3(17.7)$ \\
\hline
\end{tabular}

${ }^{\star} \mathrm{p}<0.05 ;{ }^{\star \star} \mathrm{p}<0.01 ;{ }^{\star \star \star} \mathrm{p}<0.001$ versus pre-exercise 1

$\mathrm{SF}$, shortening fraction (\%); EF, ejection fraction (\%); IRP, isovolumetric relaxation period (MS). 

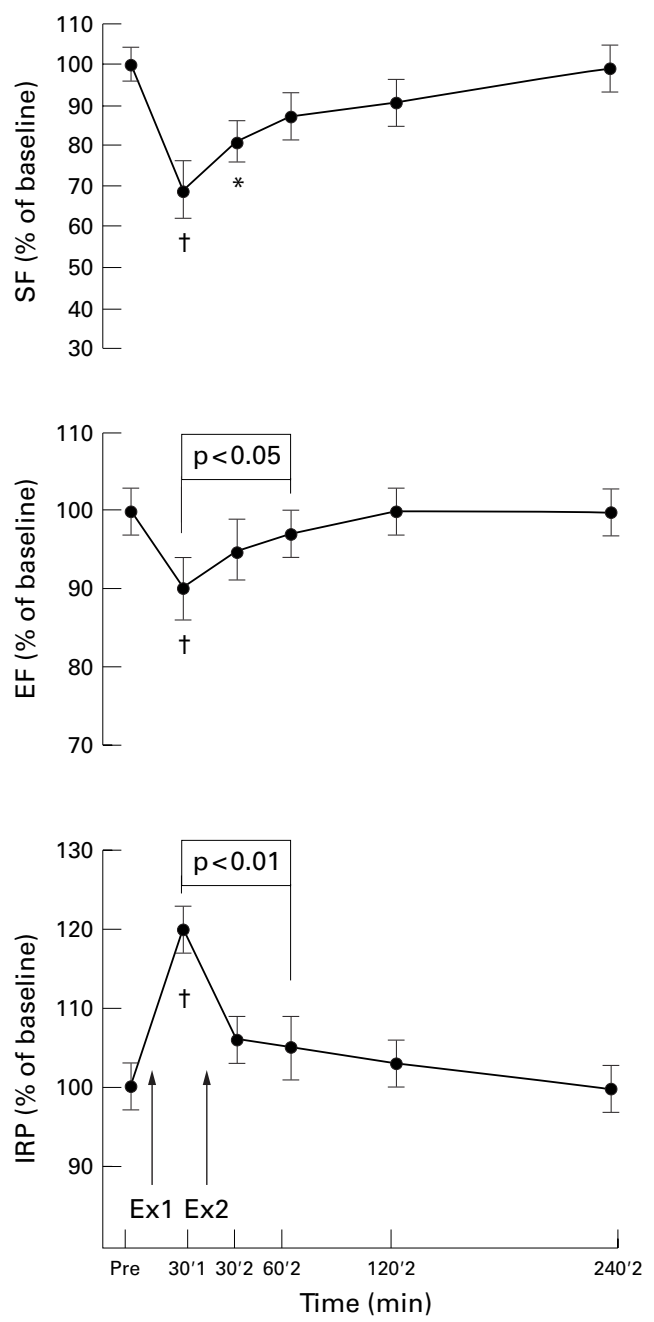

Figure 1 Echocardiographic parameters for 13 of 14 patients in group $A$ ( 30 minutes) who exhibited prolonged wall motion abnormalities (WMAs) following exercise. Data are expressed as the percentage change from baseline values (mean (SE)). SF, shortening fraction (\%) (refers to $S F$ in the segments exhibiting wall motion abnormalities - that is, SFwma); EF, ejection fraction (\%); IRP, isovolumic relaxation period (ms); Ex1, exercise 1; Ex2, exercise $2{ }^{*} p<0.05 ; t p<0.001$ versus pre Ex1.

ECHOCARDIOGRAPHIC DATA

Following Ex1 there was impaired regional and global contractile function and prolonged early relaxation consistent with myocardial stunning. These indices were not further impaired after Ex2 and recovered faster than following Ex1. There were persistent WMAs in 13 of 14 patients following Ex1 and 12 of 14 patients following Ex2. Twelve patients developed persistent WMAs after both tests, one patient developed WMAs after Ex1 but not Ex2, and one patient did not develop a WMA after either test.

Statistical comparisons of the amount of LV dysfunction between tests was performed in this group (and subsequently groups B and C) only in patients who exhibited prolonged WMAs consistent with stunning; these results are shown in table 3 and fig 1.

Global LV systolic function

Thirty minutes following Ex 1 in the 13 patients that developed WMAs there was a significant decrease in $\mathrm{EF}$ from baseline which had improved 30 minutes post Ex1 and was no longer abnormal. EF was significantly more reduced at 30 minutes post Ex1 than at 30 minutes post $\operatorname{Ex} 2(55$ (8.9) v 58.2 (8.8)\%, $\mathrm{p}<0.05)$.

\section{Regional LV systolic function}

At baseline there was no difference between SFmean and SFwma. SFwma became abnormal at both 30 minutes following Ex1 and Ex2 but had returned to normal by 60 minutes following Ex2. There were no significant changes in SFnorm from baseline following either test.

\section{Isovolumic relaxation period}

All 13 patients with abnormalities of systolic function exhibited diastolic dysfunction evidenced by a prolongation of relaxation. The IRP became prolonged at 30 minutes post $\mathrm{Ex} 1$ but had returned to normal by 30 minutes post Ex2. The IRP was significantly more prolonged at 30 minutes post Ex1 than at 30 minutes post $\operatorname{Ex} 2(105.2(10.8) v 93(10.6) \mathrm{ms}, \mathrm{p}<0.01)$.

GROUP B (60 MINUTE GROUP)

Exercise data

Both exercise tests were completed by all 14 patients. Thirteen patients experienced typical cardiac pain on exertion which led to a termination of exercise, and one patient was limited by dyspnoea. Exercise parameters and maximum ST depression did not differ significantly between Ex1 and Ex2. There were no differences in the duration of anginal pain or ST changes between tests as shown in table 2. For both tests heart rate, blood pressure, and ST changes returned to normal within 10 minutes of exercise in all cases.

\section{Echocardiographic data}

Following Ex1 there was impaired regional and global contractile function and prolonged early relaxation consistent with stunning. These indices were both more severely impaired and prolonged after Ex 2 despite equivalent exercise parameters. There were persistent WMAs in 11 of 14 patients following Ex1 and 13 of 14 patients following Ex2. Ten patients developed WMAs after both tests, one patient developed WMA abnormalities after Ex1 but not Ex2, and three patients developed WMAs after Ex2 but not Ex1. The two patients with single and two vessel disease did not develop prolonged WMAs post Ex1 but did develop WMAs after Ex2. Prolonged WMAs consistent with myocardial stunning occurred in 11 of 12 patients with triple vessel disease following Ex 1 . Table 3 shows the quantitative echocardiographic results (mean (SD)) in patients exhibiting WMAs (11/14) (fig 2).

\section{Global LV systolic function}

$\mathrm{EF}$ was significantly decreased at 30 minutes post Ex1 but had recovered by 60 minutes post Ex1. Following Ex2 EF was more severely depressed, remaining abnormal at both 30 and 60 minutes post Ex 2 and recovering by two hours following Ex2. EF was significantly more 

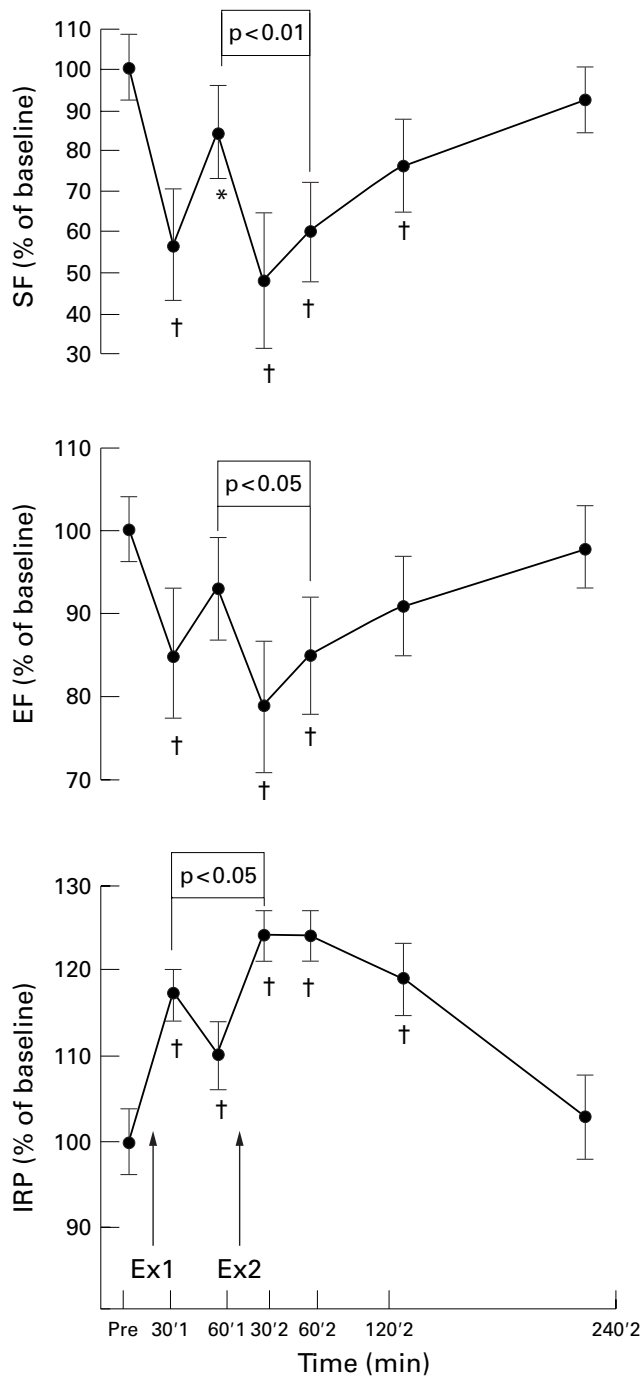

Figure 2 Echocardiographic parameters for 11 of 14 patients in group B (60 minutes) who exhibited prolonged WMAs following exercise. Data are expressed as the percentage change from baseline values (mean (SE)). ${ }^{\star} p<0.05 ; t p<0.001$ versus pre Ex1.

depressed at 60 minutes post Ex 2 compared to 60 minutes post $\operatorname{Ex1}(53.8$ (9.9) $v 48.9$ $(13.2) \%, p<0.05)$

Regional LV systolic function

At baseline there was no difference between SFmean and SFwma. SFwma was abnormal at both 30 and 60 minutes following Ex 1 and was further worsened following Ex2, remaining abnormal at both 30, 60, and 120 minutes and recovering by four hours post Ex2. SFwma was significantly more depressed at 60 minutes post Ex 2 compared to 60 minutes post Ex1 (2.81 (0.85) v $1.99(0.67) \%, \mathrm{p}<0.01)$. There were no significant changes in SFnorm from baseline after either test.

Isovolumic relaxation period

Diastolic data were available for 13 of 14 patients. All 13 patients exhibited diastolic dysfunction after both tests. The IRP became significantly prolonged at both 30 and $60 \mathrm{~min}-$ utes post Ex1 and became further prolonged at both 30 and 60 minutes post Ex2. The IRP remained abnormal at 120 minutes post Ex2 but had recovered at four hours. The IRP was significantly more prolonged at 60 minutes post Ex 2 than at 60 minutes post Ex1 (122 (12.2) v 108 (15.3) ms, p < 0.05).

GROUP C (240 MINUTE GROUP)

Exercise data

Both exercise tests were completed in all patients with 13 of 14 patients limited by angina and one patient by dyspnoea. Exercise parameters and maximum ST depression were unchanged between tests. There were close correlations between both tests for all the above parameters as shown in table 2 . For both exercises heart rate, blood pressure, and ST changes returned to baseline within 10 minutes of exercise in all cases.

Echocardiographic data

Following Ex1 there was impaired regional and global contractile function and prolonged early relaxation consistent with myocardial stunning. These changes were of similar magnitude following the two tests. There were persistent WMAs in 11 of 14 patients following Ex1 and 10 of 14 patients following Ex2. Ten patients developed WMAs after both tests, one patient developed WMA abnormalities after Ex1 but not Ex2, and three patients did not develop WMAs after either test. Table 3 shows the quantitative echocardiographic results in patients exhibiting WMAs (11/14) (fig 3).

Global LV systolic function

Following Ex1 in the 11 patients that developed WMAs there was a significant decrease in $\mathrm{EF}$ at 30 minutes post Ex1 which had recovered by 60 minutes following exercise. Thirty minutes post Ex2 EF similarly decreased and had returned to normal at $60 \mathrm{~min}-$ utes post Ex2.

\section{Regional LV function}

SFwma was abnormal at 30 minutes post Ex1 but had recovered at 60 minutes post Ex1. Following Ex2 SFwma decreased at 30 minutes and 60 minutes post Ex 2 but had returned to within normal limits by 120 minutes post Ex 2 . There were no significant changes in SFnorm from baseline after either test.

\section{Isovolumic relaxation period}

Diastolic data was available for all patients. The IRP became prolonged at both 30 and $60 \mathrm{~min}-$ utes following Ex1, but had returned to normal at 240 minutes following exercise. The IRP was similarly prolonged at both 30,60, and 120 minutes post Ex2 but had returned to normal at four hours following exercise. There were no significant differences between the severity of prolongation of the IRP between the two tests.

\section{INTER- AND INTRAOBSERVER VARIABILITY}

Inter- and intraobserver differences were small. Interobserver variability for $\mathrm{EF}$ and $\mathrm{SF}$ was calculated by comparing the measurements of two independent observers using the method of Bland and Altmann. ${ }^{8 \mathrm{~A}}$ Mean (SD) values for the two observers for EF were 61.3 (5.8)\% v 

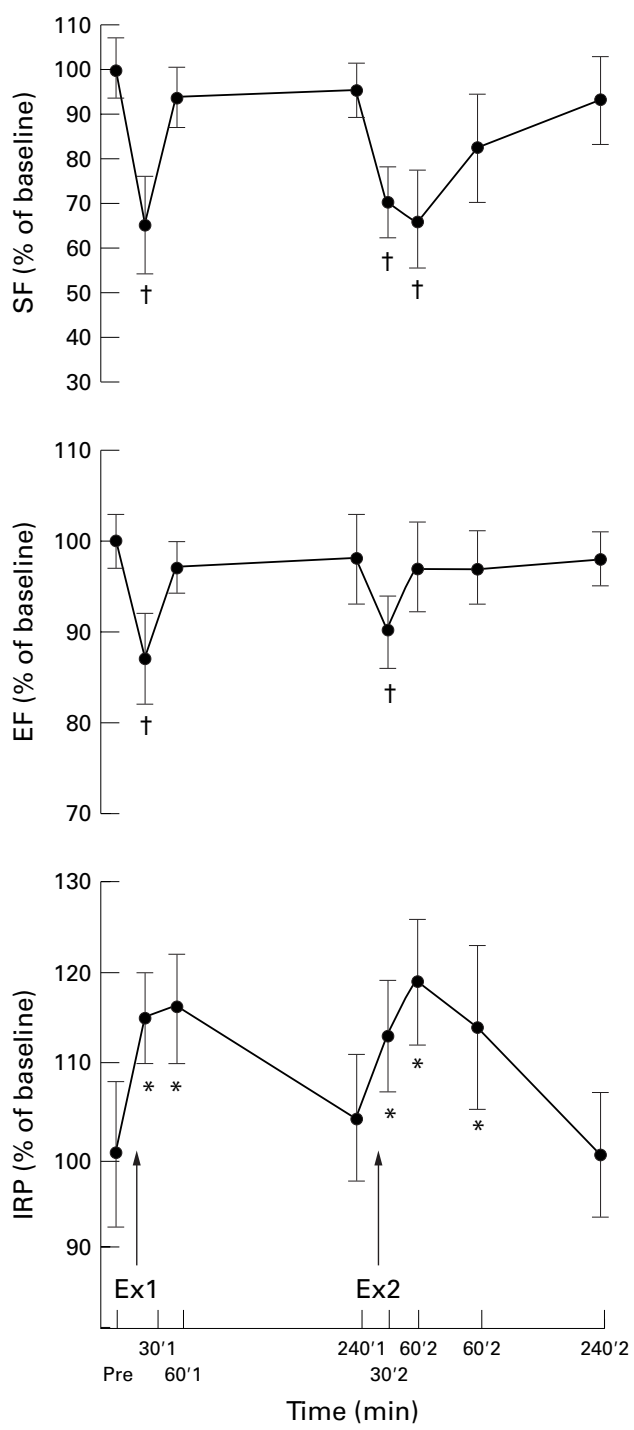

Figure 3 Echocardiographic parameters for 11 of 14 patients in group $C$ (240 minutes) who exhibited prolonged WMAs following exercise. Data are expressed as the percentage change from baseline values (mean (SE)). ${ }^{\star} p<0.05 ; t p<0.001$ versus pre Ex1.

$61.8(5.0) \%$. The mean difference between the two measurements was $0.5(4.3) \%$. Values for SF were $3.8(0.7) \%$ v $3.9(0.5) \%$ with a mean difference of $0.1(0.5) \%$.

For intraobserver variability, echocardiograms were analysed twice, at least two weeks apart, by the same observer. Values for EF were $59.2(3.9) \%$ v 60.0 (4.3)\% with a mean difference between the two measurements of 0.8 (2.3)\%. Values for SF were $3.3(0.4) \% v 3.4$ $(0.3) \%$ with a mean difference of $0.1(0.1) \%$.

\section{Discussion}

This study demonstrates that a single episode of exercise induced ischaemia produces persistent abnormalities of regional and global LV systolic function in the majority of patients, along with prolonged early relaxation. These abnormalities of LV function have a time course consistent with myocardial stunning, which has been shown to occur in patients following a single episode of effort angina. ${ }^{2}$ The effect on LV function of a second episode of exercise induced ischaemia appears to differ according to the interval between the two.

When exercise was repeated at 30 minutes following the termination of the first test, patients were able to exercise for longer and achieve a greater workload. This finding is consistent with a warm up phenomenon occurring on exercise. ${ }^{9}$ There was no significant difference in maximum ST depression between tests suggesting an equivalent ischaemic burden on both occasions. Despite equivalent degrees of ischaemia there was less exercise induced systolic and diastolic LV dysfunction on the second occasion. The absence of further dysfunction following the second exercise could have been caused by a preconditioning effect produced by the initial exercise.

ISCHAEMIC PRECONDITIONING AND WARM UP ANGINA

Ischaemic preconditioning is the phenomenon whereby a brief period of sublethal ischaemia causes the heart to adapt in such a way that it can survive a subsequent, more severe episode of ischaemia that would be expected to be lethal. ${ }^{5}$ As a result of preconditioning the heart is able to delay the onset of irreversible injury, with an approximate 20 minute shift in the occlusion time-infarct size relation. The window of protection for infarct size afforded by ischaemic preconditioning seems to last approximately 60 minutes following the preconditioning stimulus. ${ }^{10}$ Recently a second window of protection has been described which begins 24 hours after the initial event. ${ }^{11}$ The mechanism of ischaemic preconditioning is thought to involve adenosine $\mathrm{e}^{12}$ and has been expanded to include protection against other adverse consequences of ischaemia and reperfusion including reperfusion arrhythmias. ${ }^{13-16}$

Evidence for ischaemic preconditioning in the context of stunning is controversial. In open chested rabbit hearts Urabe et al demonstrated that an initial ischaemic period could precondition the heart and attenuate the stunning produced by a subsequent coronary occlusion, ${ }^{17}$ with similar results being reproduced in the rat heart. ${ }^{18}$ In canine and swine models there is no evidence that ischaemic preconditioning attenuates stunning. ${ }^{19}{ }^{20}$ It has been proposed that the beneficial effects seen in the isolated heart models may be caused by infarct size reduction with secondary improvement of LV function. ${ }^{19}$ Warm up angina is the ability of patients to exercise until they experience angina, to rest, and then to continue exertion with few or no symptoms. ${ }^{9}$ A warm up phenomenon occurs in up to $20 \%$ of patients with coronary artery disease. Objective evidence for a warm up effect in angina has been obtained by comparing haemodynamic and ECG changes during and after sequential exercise testing. In one study a warm up exercise was able to reduce the severity of myocardial ischaemia when exercise was repeated after 10 minutes, the effect still being present but significantly less marked when exercise was repeated at 30 minutes. $^{21}$ Okazaki et al 
performed two consecutive supine exercise tests separated by 15 minutes in 13 patients with left anterior descending coronary artery stenosis and found that angina, ST depression, and myocardial oxygen consumption were less on the second exercise for an equivalent amount of work, suggesting that the heart had become regionally more efficient. ${ }^{22}$ Warm up angina has been ascribed to coronary vasodilatation with the possible opening of collaterals; however, the failure of vasodilators to produce a warm up effect and the lack of correlation with collaterals on angiography does not support this suggestion. ${ }^{22}$ It has been suggested that warm up angina may actually involve the phenomenon of ischaemic preconditioning. ${ }^{23}$

Our results in the 30 minute group are consistent with a warm up phenomenon occurring on exercise, with significant improvement in exercise parameters. It is possible that the first exercise may have resulted in greater coronary dilatation during the second exercise period and that myocardial metabolism may have been more efficient. Similarly peripheral changes may have occurred resulting in a more efficient use of cardiac output and a reduction in myocardial oxygen demand, although our measurements of exercise and haemodynamic parameters do not support this. The attenuation of LV dysfunction following the second exercise demonstrated in our patients would be consistent with ischaemic preconditioning.

The findings in group B demonstrate a worsening of LV function when exercise is repeated at 60 minutes. Following the second test there were both cumulative and prolonged abnormalities of systole and diastole consistent with stunning, despite comparable amounts of ischaemia between tests. The absence of a protective effect at this time point that was present in group A 30 minutes before is consistent with the time window of protection afforded by preconditioning in most species studied-that is, less than one hour. In this group the second exercise occurred at a time when LV function had not completely returned to baseline levels. The amount of decrease in function is comparable between exercises and the cumulative decrease in LV function may be explained by the fact that the second episode of dysfunction occurred on a background of preexisting dysfunction. Nevertheless the abnormalities of function were significantly more prolonged following the second ischaemic episode.

EVIDENCE FOR CUMULATIVE LV DYSFUNCTION Repetitive coronary occlusions in animals can cause cumulative LV dysfunction. ${ }^{24-26}$ Similarly repeated exercise induced ischaemia causes cumulative LV dysfunction in a canine model with instrumented coronary stenoses. ${ }^{3}$ A recent study in chronically instrumented pigs has suggested that repeated episodes of stunning can actually produce chronic LV dysfunction. ${ }^{27}$ If this is the case in humans, then myocardial hibernation, ${ }^{28}$ traditionally thought to be a result of chronically reduced coronary flow, may be caused by repeated ischaemic events induced by an imbalance between oxygen supply and demand caused by an inadequate cor- onary flow reserve. ${ }^{27}$ Ambulatory ECG studies have suggested that patients with unstable coronary artery disease may experience up to 10-20 episodes of ischaemia daily ${ }^{29}$; under such conditions the myocardium could become chronically depressed. However, this may not be fully applicable to patients with chronic stable angina as in our study group.

In humans, support for the hypothesis that chronic myocardial dysfunction may be secondary to repeated stunning is provided by studies using positron emission tomography. ${ }^{4031}$ Tillisch et al demonstrated that $37 \%$ of chronically dysfunctional or "hibernating" segments had normal resting blood flow and $88 \%$ of these improved following coronary artery bypass grafting. ${ }^{30}$ Vanoverschelde et al demonstrated chronically depressed wall motion in non-infarcted, collateral dependent myocardium despite having near normal resting blood flow and oxygen consumption, ${ }^{4}$ and Marinho et al demonstrated that resting myocardial blood flow in chronically dysfunctional segments is not reduced. ${ }^{31}$ If repeated episodes of exercise induced stunning produce cumulative and prolonged abnormalities in humans then stunning could be an important cause of significant and persistent LV dysfunction occurring on a regular basis in patients with coronary artery disease.

The results from group $C$ suggest that if the myocardium is allowed sufficient time to recover between episodes of ischaemia-in this case four hours - the effect of ischaemia on LV function is similar for both tests. In group $C$ the abnormalities of function had completely returned to normal by the time of the second exercise and the amount of LV dysfunction was comparable. There did, however, still appear to be some cumulative effect on LV function as witnessed by the delayed recovery of function after Ex2. The reason for performing exercise at this time point is that contractile abnormalities caused by stunning following a single episode of angina take between 60 and 120 minutes to return to normal. ${ }^{232}$ Diastolic abnormalities, however, appear to be more prolonged. We have demonstrated different rates of resolution of systolic and diastolic dysfunction following exercise induced ischaemia, with diastolic abnormalities of early relaxation and filling persisting for up to four hours following a single episode of angina. ${ }^{32} \mathrm{We}$ therefore elected to perform repeated exercise in group $\mathrm{C}$ at a time when all functional abnormalities caused by the first exercise should have fully resolved.

\section{LIMITATIONS OF THE STUDY}

No absolute measurements of perfusion were performed following repeated exercise, although all haemodynamic parameters and ST depression had returned to normal at a time when LV dysfunction persisted. We and others have simultaneously demonstrated myocardial dysfunction in the presence of normal perfusion at 30 minutes postexercise, thus demonstrating that LV dysfunction at this time point is caused by stunning. ${ }^{2}{ }^{32}$ Although we cannot 
be certain that the abnormalities of function were caused by stunning in this study, the presence of abnormalities 30 minutes postexercise is consistent with our previous findings and those of others which demonstrate that $\mathrm{LV}$ dysfunction at this time is caused by stunning. There are limitations to the use of endocardial wall excursion as the sole criterion of abnormal contractile function; neither wall thickening nor transmyocardial heterogeneity is taken into account. However, it does provide a quantitative method that is repeatable and it is likely that only subtle abnormalities of regional LV function are missed.

There are limitations to using IRP as a sole index of diastolic function. Its prolongation signifies abnormal relaxation which is a well documented effect of ischaemia on diastolic function. It is, however, influenced by systolic function and incoordinate wall motion will prolong isovolumic relaxation. We have found that, in patients with prolongation of the IRP, this remained abnormal well after the recovery of systolic function. It is possible that this simply reflects greater sensitivity in the measurement of IRP compared to shortening fraction or may be related to differences in the mechanisms of systolic and diastolic stunning.

\section{CONCLUSIONS}

Our data demonstrate for the first time that repetitive episodes of exercise induced ischaemia in patients with chronic stable angina can produce repeated episodes of LV dysfunction with a time course consistent with myocardial stunning. The effect on LV function appears dependent on the time between ischaemic periods and our results may give some insight into the possible underlying mechanism for chronic LV dysfunction in patients with coronary artery disease.

This work was supported by a project grant from the British Heart Foundation

1 Bolli R. Myocardial "stunning" in man. Circulation 1992;86:1671-91.

2 Ambrosio G, Betocchi G, Pace L, et al. Prolonged impairment of regional contractile function after resolution of exercise-induced angina: evidence of myocardial stunning in patients with coronary artery disease. Circulation 1996;94:2455-64.

3 Homans DC, Laxson DD, Sublett E, et al. Cumulative deterioration of myocardial function after repeated episodes of exercise induced ischemia. Am 7 Physiol 1989;256:H146271 .

4 Vanoverschelde J-LJ, Wijns W, Depre C, et al. Mechanisms Vanoverschelde J-LJ, Wijns W, Depre C, et al. Mechanisms
of chronic regional postischemic dysfunction in humans. of chronic regional postische
Circulation 1993;87:1513-23.

5 Murry CE, Jennings RB, Reimer KA. Preconditioning with ischemia: a delay of simple lethal cell injury in ischemic myocardium. Circulation 1986;74:1124-36.

6 Assman PE, Slager CJ, van der Borden SG, et al. Quantitative echocardiographic analysis of global and regional left ventricular function: a problem revisited. $\mathcal{f} \mathrm{Am}$ Soc Echocardiogr 1990;3:478-87.
7 Sheehan FH, Bolson EL, Dodge HT. Advantages and applications of the centerline method for characterizing regional cations of the centerline method for characterizing
ventricular function. Circulation 1986;74:293-305.

8 McGillem M, Mancini J, DeBoe SF, et al. Modification of centreline method for assessment of echocardiographic wall thickening and motion: a comparison with areas of risk. I Am Coll Cardiol 1988;11:861-6.

8A Bland JM, Altmann DG. Statistical methods for assessing agreement between two methods of clinical measurement. Lancet 1986;i:307-10.

9 MacAlpin RN, Kattus AA. Adaptation to exercise in angina pectoris. Circulation 1966;33:183-201.

10 Lawson CS, Downey JM. Preconditioning: state of the art myocardial protection. Cardiovasc Res 1993;27:542-50.

11 Baxter GF, Marber MS, Patel VC, et al. Adenosine receptor involvement in a delayed phase of myocardial protection 24 hours after ischemic preconditioning. Circulation 1994;90: 2993-3000.

12 Downey JM, Liu GS, Thornton JD. Adenosine and the antiinfarct effects of preconditioning. Cardiovasc Res 1993;27: $3-8$.

13 Lawson CS, Coltart DJ, Hearse DJ. "Dose" dependency and temporal characteristics of protection by ischaemic preconditioning against ischaemia induced arrhythmias in rat hearts. F Mol Cell Cardiol 1993;25:1391-402.

14 Lawson CS, Avkiran M, Shattock MJ, et al. Preconditioning and reperfusion arrhythmias in the isolated rat heart: true protection or temporal shift in vulnerability? Cardiovasc Res protection or temp

15 Shiki K, Hearse DJ. Preconditioning of ischemic myocardium: reperfusion induced arrhythmia. Am f Physiol 1987;253:H1470-6

$16 \mathrm{Li} \mathrm{Y,} \mathrm{Kloner} \mathrm{RA.} \mathrm{Cardioprotective} \mathrm{effects} \mathrm{of} \mathrm{ischemic}$ preconditioning are not mediated by prostanoids. Cardiovasc Res 1992;26:226-31.

17 Urabe K, Miura T, Iwamoto $\mathrm{T}$, et al. Preconditioning enhances myocardial resistance to postischemic myocardial stunning via adenosine receptor activation. Cardiovasc Res 1993;27:657-62.

18 Lasley RD, Anderson GM, Mentzer RM. Ischemic and hypoxic preconditioning enhance postischemic recovery of function in the rat heart. Cardiovasc Res 1993;27:565-70.

19 Ovize M, Przyklenk K, Hale SL, et al. Preconditioning does not attenuate myocardial stunning. Circulation 1992;85: $2247-54$.

20 Miyamae M, Fujiwara H, Kida M. Preconditioning improves energy metabolism during reperfusion but does not attenuate myocardial stunning in porcine hearts. Circulation 1993;88:223-34.

21 Stewart RA, Simmonds MB, Williams MJA. Time course of "warm-up" in stable angina. Am f Cardiol 1995;76:70-4.

22 Okazaki Y, Kodama K, Sato H, et al. Attenuation of increased regional myocardial consumption during exercise as a major cause of warm-up phenomenon. $7 \mathrm{Am}$ Coll Cardiol 1993;21:1579-604.

23 Marber MS, Joy MD, Yellon DM. Is warm-up in angina ischaemic preconditioning? Br Heart f 1994;72:213-15.

24 Becker LC. Do neutrophils contribute to myocardial stunning? Cardiovasc Drugs Ther 1991;5:909-13.

25 Nicklas JM, Becker LC, Bulkley BH. Effects of repeated brief coronary occlusion on regional left ventricular function and dimension in dogs. Am 7 Cardiol 1985;56: 473-8.

26 Geft IL, Fishbein K, Ninomiya J, et al. Intermittent brief periods of ischemia have a cumulative effect and may cause myocardial necrosis. Circulation 1982;66:1150-60.

27 Shen Y-T, Vatner SF. Mechanism of impaired myocardial function during progressive coronary stenosis in conscious pigs. Hibernation versus stunning. Circ Res 1995;76:479pigs.

28 Rahimtoola SH. The hibernating myocardium. Am Heart $\mathcal{f}$ 1989;117:211-21.

29 Gottlieb SO, Weisfeldt SM, Ouyang P, et al. Silent ischemia as a marker for early unfavourable outcomes in patients with unstable angina. $N$ Engl 7 Med 1986;314:1214-19.

30 Tillisch J, Brunken R, Marshall R, et al. Reversibility of cardiac wall motion abnormalities predicted by positron tomography. N Engl f Med 1986;314:884-8.

31 Marinho NVS, Keogh BE, Costa DE, et al. Pathophysiology of chronic left ventricular dysfunction. Circulation 1996; of chronic

32 Masani ND, Jones RA, Hall RJC. Exercise induced myocardial stunning: differential rates of systolic and diastolic recovery [abstract]. Br Heart f 1994;71(suppl):78. 